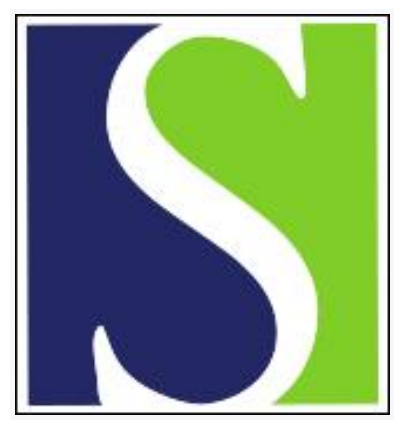

Scand J Work Environ Health 2015;41(4):397-406

https://doi.org/10.5271/sjweh.3507

Published online: 05 Jun 2015, Issue date: 01 Jul 2015

Occupational exposures and sick leave during pregnancy: results from a Danish cohort study

by Hansen ML, Thulstrup AM, Juhl M, Kristensen JK, Ramlau-Hansen CH

This paper adds to the limited literature on specific occupational exposures and risk of sick leave during pregnancy. The paper is based on a large population-based cohort of pregnant women with the opportunity to adjust for a number of potential confounders. The occupational exposures are based on self-reports and give the opportunity to investigate dose-response relations.

Affiliation: Department of Occupational Medicine, Noerrebrogade 44, building 2C, Aarhus University Hospital, Aarhus, Denmark. methasen@rm.dk

Refers to the following texts of the Journal: 1995;21(3):191-198 2015;41(2):184-193 1997;23(5):378-384 2009;35(5):325-333 2013;39(4):325-334 2013;39(4):335-342 2014;40(4):411-419

The following article refers to this text: $2020 ; 46(1): 60-68$

Key terms: cohort study; Denmark; job strain; night shift; occupational exposure; occupational lifting; pregnancy; sick leave; sickness absence; sickness absence; work posture; work shift

This article in PubMed: www.ncbi.nlm.nih.gov/pubmed/26047490 


\title{
Occupational exposures and sick leave during pregnancy: results from a Danish cohort study
}

\author{
by Mette Lausten Hansen, MD, ${ }^{1}$ Ane Marie Thulstrup, PhD, ${ }^{1}$, Mette Juhl, PhD, ${ }^{2}$ Jette Kolding Kristensen, \\ $P h D,{ }^{3}$ Cecilia Høst Ramlau-Hansen, $P h D^{4}$
}

\begin{abstract}
Hansen ML, Thulstrup AM, Juhl M, Kristensen JK, Ramlau-Hansen CH. Occupational exposures and sick leave during pregnancy: results from a Danish cohort study. Scand J Work Environ Health. 2015;41(4):397-406. doi:10.5271/sjweh.3507
\end{abstract}

\begin{abstract}
Objective This study aimed to investigate associations between work postures, lifting at work, shift work, work hours, and job strain and the risk of sick leave during pregnancy from 10-29 completed pregnancy weeks in a large cohort of Danish pregnant women.

Methods Data from 51874 pregnancies in the Danish National Birth Cohort collected between 1996-2002 were linked to the Danish Register for Evaluation of Marginalization. Exposure information was based on telephone interviews. Hazard ratios (HR) with $95 \%$ confidence intervals $(95 \% \mathrm{CI})$ were calculated by Cox regression analysis, using time of first episode of sick leave as the primary outcome.

Results We found statistically significant associations between all the predictors and risk of sick leave; for nonsitting work postures $\left(\mathrm{HR}_{\text {range }} 1.55-2.79\right)$, cumulative lifting $\mathrm{HR}_{\text {trend }} 1.29,95 \% \mathrm{CI} 1.26-1.31$, shift work $\left(\mathrm{HR}_{\text {evening }}\right.$

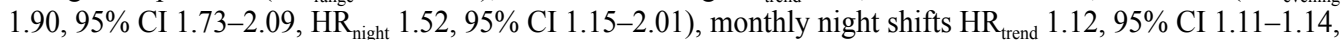
increasing weekly work hours $\mathrm{HR}_{\text {trend }} 0.93,95 \%$ CI $0.91-0.95$ and high job strain HR $1.52,95 \%$ CI 1.42-1.63. Some exposures influenced HR in either a positive or negative time-dependent way.

Conclusion Our results support previous findings and suggest that initiatives to prevent sick leave during pregnancy could be based on work conditions. Preventive measures may have important implications for pregnant women and workplaces.
\end{abstract}

Key terms Denmark; job strain; night shift; occupational lifting; sickness absence; work posture; work shift.

Sick leave during pregnancy is frequent, and the number of pregnant women on sick leave has increased during the past decades without clear medical explanations $(1-5)$. This is surprising given today's focus on work conditions and current legislation both in Denmark and Europe, which demands that employers assess and control safety factors that constitute a risk to pregnant women's health. A number of factors such as course of pregnancy (6), attitudes towards sick leave $(2,7)$, levels of social benefits $(7,8)$, body mass index (BMI), and assisted reproductive therapy (ART) (9) have been found to be predictive of sick leave during pregnancy. Occupational exposures $(3,6)$ have also been associated with sick leave during pregnancy, and modifications in occupational exposures have been found to reduce the risk of sick leave during pregnancy $(10,11)$. However, the association between specific occupational exposures and risk of sick leave during pregnancy remains a remarkably unexplored issue, and results from the available literature show that the prevalence of sick leave varies much between occupations $(3,6,12)$. The existing literature is characterized by the use of rough measures of occupational exposures and limited or no adjustment for potential confounders. Moreover, studies are often limited to certain trades and are small in size, which emphasizes the need for more research in this area (3, $6,12)$. It is important to identify possible associations between occupational exposures and sick leave during pregnancy because such findings may have important implications in preventing sick leave.

1 Department of Occupational Medicine, Danish Ramazzini Centre, Aarhus University Hospital, Aarhus, Denmark.

2 Midwifery Department, Metropolitan University College, Copenhagen, Denmark.

3 Department of Public Health, Section of General Practice, Aarhus University, Aarhus, Denmark.

4 Department of Public Health, Section for Epidemiology, Aarhus University, Aarhus, Denmark.

Correspondence to: Mette Lausten Hansen, Department of Occupational Medicine, Noerrebrogade 44, building 2C, Aarhus University Hospital, Aarhus, Denmark. [E-mail: methasen@rm.dk] 
We aimed to investigate associations between work posture, lifting at work, shift work, work hours, and job strain, and the risk of sick leave from 10-29 completed pregnancy weeks in a large population-based cohort of pregnant women.

\section{Methods}

\section{Study population}

We used data from the Danish National Birth Cohort (DNBC), a nation-wide cohort study including 100418 pregnancies enrolled between 1996-2002. Pregnant women were invited to participate at their first antenatal visit at the general practitioner. The inclusion criteria were (i) Danish residency, (ii) planning to complete the pregnancy, and (iii) sufficient fluency in Danish to participate in four telephone interviews. The initial data collection included four interviews, three blood samples, and a food frequency questionnaire. Two interviews were conducted during pregnancy (around pregnancy week 17 and 30) and two postpartum (6 and 18 months). The cohort is described in detail elsewhere (13).

In this study, we included pregnancies of women gainfully employed at the time of first pregnancy interview. For a detailed definition of the study population, see figure 1 . The final study population consisted of 51874 pregnancies among 49708 employed women as some women participated in the data collection with more than one pregnancy. The Scientific Ethical Committee approved the cohort, and the Danish Data Protection Agency and the Steering Committee of the DNBC approved storage, handling, and linkage of data for the present study (approval no. 2012-41-0086 and 2012-06).

\section{Occupational exposures}

All independent variables came from the first pregnancy interview (in completed pregnancy weeks: 18 (mean); 17 (median); $25^{\text {th }}$ percentile $=14 ; 75^{\text {th }}$ percentile $\left.=20\right)$. The following questions were used (translated from Danish): (i) Work posture: "In your job, do you sit, stand, or walk most of the time, or can you change as you like?" (Answer categories were: Primarily standing, primarily walking, primarily standing and walking, primarily sitting, I can change as I wish.) (ii) Lifting: "In your job, do you daily lift $>20 \mathrm{~kg}$ at a time? (Approximately like a crate of beer.)" If yes, "How many times a day do you lift $>20 \mathrm{~kg}$ ?" "Do you have daily lifts of between 11-20 $\mathrm{kg}$ ? (Less than a crate of beer and more than a bucket of water.) If yes, "How many times a day do you lift between 11-20 kg?" (iii) Work shift: "What are your normal working hours, day, evening or night, or do you have shifting working hours?" (Answer categories were: day, evening, night, shifting not night, shifting including night.) "How often do you work at night?" (Answer categories were: less than once a month, number of shifts per month.) (iv) Weekly work hours: "How many hours a week do you work?" Job strain was estimated by using Karasek's job demand and job control model (14). This model has previously been used on DNBC data for assessment of late foetal loss, pelvic pain, and adverse birth outcomes (15-17). The model combines job demands and job control into four categories of job strain: relaxed (low demands/high control), passive (low demands/low control), active (high demands/high control) and strained (high demands/low control). Relaxed refers to low-strain jobs and strained refers to high-job strain. Demands and control dimensions were derived from the questions: "Do you feel overworked in your job?" (demand dimension), "Do you have any influence on your working conditions?" (control dimension). (For both dimensions, answer categories were: often, from time to time, seldom.) High demands were defined by the "often" answer category and low control by the "seldom" answer category.

All variables that were answered "do not know" or "do not want to answer" were coded as missing.

\section{Sick leave}

In Denmark, sickness during pregnancy is classified as either sick leave or pregnancy-related sick leave; the latter is due to either an abnormal course of pregnancy or the presence of work environment conditions that are potentially harmful during pregnancy. We used the Danish Register for Evaluation of Marginalisation (DREAM) to measure sick leave (18). DREAM contains weekly information on $>100$ types of social benefit payments, each characterized by a unique code. A registration of sick leave in DREAM is conditional on reimbursement for employed citizens. At the time of data collection, reimbursement was conditioned on a minimum of two weeks of consecutive sick leave paid by the employer. Thus, sick leave of $<15$ consecutive days was not registered in DREAM, however, if the sick leave lasted $>15$ days, the episodes were registered from the first day. Regarding pregnancy-related sick leave, employers received reimbursement from the first day of sick leave. These variations in sick-leave registration according to sick leave motivation, lead to an underestimation of sick leave prevalence. Furthermore, a weekly registration in DREAM requires merely one day of sickness benefit payment during the week in question.

For each completed pregnancy week from 10-29, we estimated sick leave for gainfully employed women using the following DREAM codes: 774 (sick leave from flexi-jobs, ie, jobs for citizens with reduced abil- 


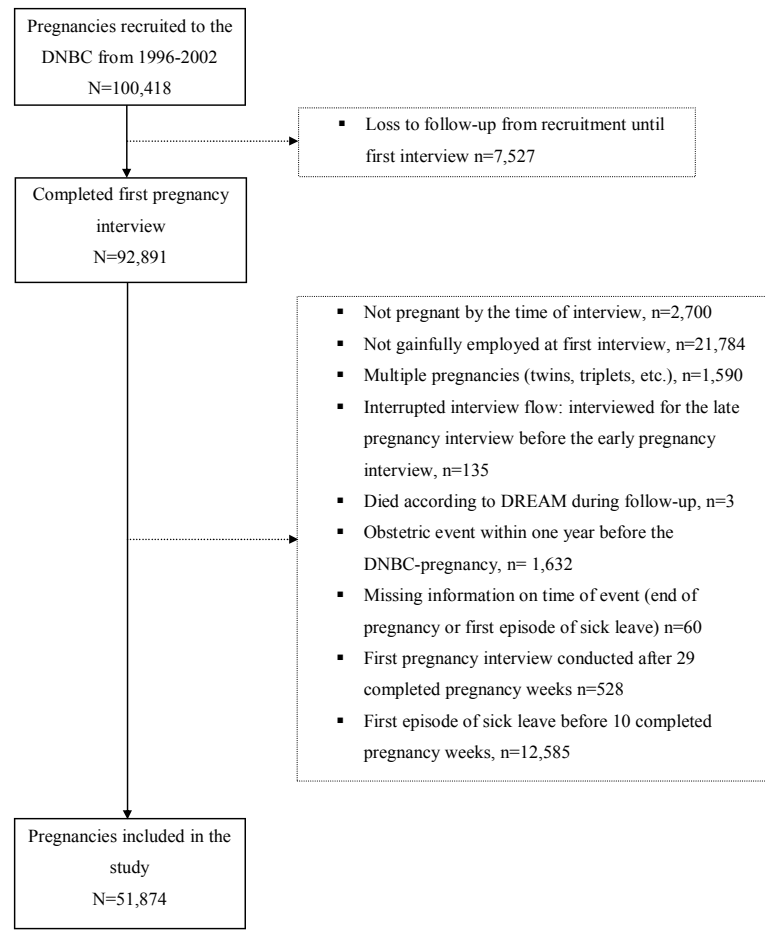

Figure 1. Number of pregnancies included in the study.

ity to work because of chronic illness), 881 (maternity leave and pregnancy-related sick leave), 890, 892, 893, 894, 895, 896, 897, 898, and 899 (all sick leave codes for either ordinary employment, various job training programs or apprenticeships) (18) .

The time of the first episode of sick leave from 10-29 completed pregnancy weeks was the primary outcome in our study. The lower boundary was chosen because, according to the Danish antenatal care program, most women were invited to participate in DNBC at 10 completed pregnancy weeks. Some Danish women start maternity leave at 31 completed pregnancy weeks according to their collective agreements. Since maternity leave and pregnancy-related sick leave have the same DREAM code, we decided on the upper boundary of 29 completed pregnancy weeks.

\section{Potential confounders}

Adjustments were made for several a priori selected potential confounders based on the literature: age, daily smoking, weekly intake of alcoholic drinks, occupational class as a proxy measure for socioeconomic status, sick leave prior to the DNBC pregnancy, chronic diseases, parity, pre-pregnancy BMI, ART, and receiving support from colleagues at work.

Age was the women's age at the time of the first pregnancy interview. Self-reported alcohol intake [drinks/week (continuous)] and daily tobacco smoking [yes/no (reference)] were generated from questions in the first pregnancy interview. As a proxy for socioeconomic status, occupational class was used in four categories [unskilled workers, skilled workers, lower grade professionals, higher grade professionals (reference)]. Occupational class was based on educational level and the Danish version of the International Standard Classification of Occupations (DISCO-88). If educational level or DISCO-88 codes were missing, information for the spouse or cohabiting partner was used; the pregnant women provided information on the spouse at the first interview. Sick leave prior to the DNBC pregnancy was assessed using DREAM data. We included information 104 weeks back in time from the onset of the DNBC pregnancy and counted the number of weeks each woman received sickness benefit payment (excluding pregnancy benefits). The prior sick leave variable was categorized into five groups [0 weeks (reference), 1-4 weeks, 5-8 weeks, 9-25 weeks and $\geq 26$ weeks]. "Chronic diseases" [yes/no (reference)] was generated from information on self-reported diseases and included cardiovascular, metabolic, musculoskeletal, epilepsy, and psychiatric disorders as well as other diseases classified as severe. Parity (nulliparous (reference)/ multiparous) and ART [yes/no (reference)] was based on information about earlier births and receiving fertility treatment. BMI $\left(\mathrm{kg} / \mathrm{m}^{2}\right)$ was calculated as pre-pregnancy weight $(\mathrm{kg}) /\left[\right.$ height $\left.\left(\mathrm{m}^{2}\right)\right]$ and was grouped according to WHO classification: underweight (BMI $<18.5 \mathrm{~kg} /$ $\mathrm{m}^{2}$ ), normal weight [BMI $18.5-<25 \mathrm{~kg} / \mathrm{m}^{2}$ (reference)], overweight (BMI $25-<30 \mathrm{~kg} / \mathrm{m}^{2}$ ) and obese (BMI $\geq 30$ $\mathrm{kg} / \mathrm{m}^{2}$ ). Finally, collegial support [often (reference), from time to time, seldom] was based on the question "Do you get any help from colleagues when you have troubles at work?"

\section{Statistical analysis and data modelling}

Data were analyzed by a multivariable Cox regression model, using pregnancy week as the underlying time variable. Calculation of pregnancy week was based on the self-reported due date from the first pregnancy interview. If these data were missing, data from the late pregnancy interview were used. The due data was based on the last menstrual period.

Time at risk started at the time of the first pregnancy interview and ended at the first episode of sickness leave, pregnancy termination (miscarriage or induced abortion $<22$ competed pregnancy weeks), preterm delivery (birth $>22-<37$ completed pregnancy weeks), or still birth (birth after 22 completed pregnancy weeks) or end of the study period at 29 completed pregnancy weeks, whichever came first. Pregnancies of women on sick leave at the time of the first pregnancy interview were excluded from the analyses. 
Risk estimates are presented as crude and adjusted hazard ratios (HR) for the whole study period and for four pre-defined pregnancy periods; $(10-14,15-19$, 20-24, and 25-29 completed weeks). Trend test estimates represent the following unit changes: cumulative daily lifting (one-unit change in lifting category), average weekly night shifts (one-unit change in average number of monthly shifts), and weekly work hours (one-unit change in work hour category). We calculated time-varying coefficients for all the exposures to estimate time-dependent effects of the exposures with time since 10 completed pregnancy weeks. Finally, we made three sub-analyses, where we (i) adjusted for selected pregnancy-related disorders (vaginal bleeding, painful Braxton Hick's contractions, threatening preterm labor, nausea, and vomiting), (ii) excluded duplicate pregnancies of women who participated more than once in DNBC, and (iii) adjusted for the other occupational exposures. We included the pregnancy-related disorders because they are independent risk factors for sick leave, however some of the disorders could also be intermediate factors (eg, Braxton Hick's contractions). Data on the pregnancy-related disorders were obtained from the second pregnancy interview at (mean) 32.2 completed pregnancy weeks.

Data were analyzed using STATA version 13.0 (STATA Corp LP, College Station, Texas, USA).

\section{Results}

The cumulative incidence proportion of sick leave was $36.1 \%$ from onset of pregnancy until 29 completed pregnancy weeks. Table 1 describes sick leave prevalence week by week from 10-29 completed pregnancy weeks. Owing to staggered pregnancy week entry in $\mathrm{DNBC}$, few pregnancies were observed in the earliest completed pregnancy weeks. The prevalence of sick leave increased from $2 \%$ to $17 \%$ during the pregnancy time span.

Table 2 gives a description of the pregnancies according to first episode of sick leave or no sick leave between 10 and 29 completed pregnancy weeks. There were a total of 10667 pregnancies with at least on episode of sick leave. Small differences in mean pregnancy week and mean age at the first interview were seen between the sick leave groups. Sick leave was more frequent among smokers, alcohol abstainers, and among either skilled or unskilled workers. Sick leave before the DNBC pregnancy, chronic diseases, multiparity, overweight, and obesity and were all more frequent in pregnancies with compared to without sick leave.

Table 3 shows $\mathrm{HR}_{\text {crude }}$ and $\mathrm{HR}_{\text {adj }}$ with $95 \%$ confidence intervals $(95 \% \mathrm{CI})$ for first episode of sick leave from
10-29 completed pregnancy weeks. Adjusted results are presented in two models, respectively excluding and including occupational class. In the fully adjusted model including occupational class, work postures, daily lifts $(>20 \mathrm{~kg})$ and daily lifts $(11-20 \mathrm{~kg})$, and all levels of cumulative daily lifting were found to be associated with increased HR of sick leave compared with the reference groups. Trend for cumulative daily lifting showed a positive dose-response relation of $1.29,95 \%$ CI 1.27-1.31. Non-daytime work hours and shift work were associated with increased HR for sick leave, and a dose-response relation was seen between increasing number of monthly night work shifts and hazards for sick leave $1.04,95 \%$ CI 1.04-1.05. Working $>37$ hours per week was associated with decreased HR for sick leave compared with women working 37 hours weekly, and, moreover, the relation between increasing work hours and HR was negatively dose-dependent $0.93,95 \%$ CI 0.91-0.95. Finally, an association was found between high job strain and increasing HR for sick leave 1.51, 95\% CI 1.41-1.62. In the model where we did not adjust for occupational class, the associations were stronger for most exposures compared to the fully adjusted model.

The study period was split into four time periods to evaluate time-dependent effects of the exposures measured by time-varying coefficients (table 4). The few participants in the early pregnancy interval are reflected in the wide confidence intervals. Compared with the reference groups, we found increased HR for sick leave in all four time periods for all work postures, daily lifts $>11$ $\mathrm{kg}$, cumulative daily lifting $>14 \mathrm{~kg}$ and highly strained jobs. Furthermore, the results indicated time-dependent effects: HR decreased with time for work postures classified as "other", daily lifts $>11$ and $20 \mathrm{~kg}$ and job strain classified as "passive", and HR increased with shifting work hours with and without night shifts.

We did not adjust for pregnancy-related disorders in our main analyses, as we had no such information by the time of the first pregnancy interview. In a sub-analysis, we used data from the late-pregnancy interview (median 32.3 pregnancy weeks) to adjust for self-reported pregnancy complications. This adjustment did not change the results appreciably (data not shown). In another sub-analysis, the analysis was restricted to the first DNBC pregnancy for women participating more than once in the DNBC; this neither changed the results considerable (data not shown). Finally, we adjusted for all other occupational exposures to estimate independent effects of the individual exposures. Occupational lifting and shift work were not mutually adjusted for all other occupational exposures due to possible close correlation with some of the other exposures. Adjustment for occupational exposure adjustment attenuated most of the results. Compared to the results in table 3, the HR decreased by $8-26 \%$ for work postures, $20-30 \%$ for 
Table 1. Prevalence of sick leave according to pregnancy week from 10-29 completed pregnancy weeks ( $\mathrm{N}=51874)$. Pregnancies are counted from time of first pregnancy interview.

\begin{tabular}{|c|c|c|c|c|}
\hline \multirow[t]{2}{*}{$\begin{array}{l}\text { Pregnancy } \\
\text { week }\end{array}$} & \multicolumn{2}{|c|}{$\begin{array}{l}\text { Pregnancies with } \\
\text { sick leave }\end{array}$} & \multirow{2}{*}{$\begin{array}{c}\text { Prevalence of } \\
\text { sick leave } \\
\%\end{array}$} & \multirow{2}{*}{$\begin{array}{c}\text { Total number of } \\
\text { pregnancies } \\
\text { observed a }\end{array}$} \\
\hline & Yes & No & & \\
\hline 10 & 4 & 200 & 2.0 & 204 \\
\hline 11 & 35 & 1416 & 2.4 & 1451 \\
\hline 12 & 86 & 4189 & 2.0 & 4275 \\
\hline 13 & 189 & 8581 & 2.2 & 8770 \\
\hline 14 & 341 & 13461 & 2.5 & 13802 \\
\hline 15 & 524 & 18566 & 2.7 & 19090 \\
\hline 16 & 787 & 23364 & 3.3 & 24151 \\
\hline 17 & 1041 & 27802 & 3.6 & 28843 \\
\hline 18 & 1343 & 31712 & 4.1 & 33055 \\
\hline 19 & 1719 & 35162 & 4.7 & 36881 \\
\hline 20 & 2200 & 38021 & 5.5 & 40221 \\
\hline 21 & 2686 & 40373 & 6.2 & 43059 \\
\hline 22 & 3213 & 42015 & 7.1 & 45228 \\
\hline 23 & 3781 & 43210 & 8.1 & 46991 \\
\hline 24 & 4493 & 43848 & 9.3 & 48341 \\
\hline 25 & 5300 & 44062 & 10.7 & 49362 \\
\hline 26 & 6136 & 43919 & 12.3 & 50055 \\
\hline 27 & 6962 & 43631 & 13.8 & 50593 \\
\hline 28 & 7871 & 43060 & 15.5 & 50931 \\
\hline 29 & 8793 & 42377 & 17.2 & 51170 \\
\hline
\end{tabular}

lifting and work shift, $20-36 \%$ for average number of night shifts and $6-10 \%$ for work hours. Work exposure adjustment changed the results for job strain in different directions, HR for high job strain decreased by $10 \%$, whereas HR for passive and low job strain increased by $3-6 \%$. With the exception of average number of night shifts, weekly work hours and job strain all results were still statistically significant after mutual occupational exposure adjustment.

\section{Discussion}

We found that non-sitting work postures, lifting, shift work, number of night shifts, and high job strain were associated with an increased risk of sick leave, while working $>37$ weekly work hours was associated with a lower risk of sick leave.

The cumulative incidence proportion of sick leave from the beginning of pregnancy until 29 completed weeks $(36.1 \%)$ reported here is in accordance with results from the Norwegian Mother and Child Cohort Study (MoBa) (36.2\%) (10). Two Swedish studies found similar proportions ranging from $29-37 \%(6$, $19)$, whereas studies from Norway found much higher proportions $71-75 \%(12,20)$. However, the use of different cut-off points for sick leave in the studies hampers comparison of results. We believe that the cumulative incidence proportion in our study underestimates the true proportion because of the omission of short sick leave spells in DREAM.

Our results on occupational exposures are in the same direction as results from earlier studies investigating associations between specific occupational exposures and sick leave $(3,12)$. Kærlev et al (3) studied sick leave among Danish hospital employees and found higher odds ratios (OR) for $>10 \%$ sick leave from scheduled work among women exposed to heavy lifting 1.90 (95\% CI 1.3-2.9), walking or standing work 3.4 (95\% CI 1.9-5.8), and working nights or having shift work 2.3 (95\% CI 1.5-3.5) (3). Strand et al (12) found higher OR for sickness certification before delivery among women who had shift work 1.51 (95\% CI 1.19-1.93) and lifted heavy loads (10-20 kg) 1.48 (95\% CI 1.22-1.80). However, Strand et al used retrospectively collected exposure data, which could involve risk of recall bias (12). Exposure information in the DNBC gave us the opportunity to study dose-response relations for cumulative daily lifting, shift work, and weekly work hours. We found that exposure to medium amounts of cumulative daily lifting was associated with increased HR of sick leave 1.53 (95\% CI 1.42-1.65), a low number of monthly night shifts was associated with higher risk for sick leave 1.39 (95\% CI1.12-1.73), and working $>37$ hours decreased the HR 0.79 (95\% CI 0.74-0.85). The lower HR among women working $>37$ hours weekly could potentially be caused by a healthy worker effect, but may also be related to higher motivation or different job types among these women.

Our results are in accordance with findings in populations of non-pregnant working women and even men (21-24). Comparability between studies is, however, limited by differences in exposure classification, outcome definitions and adjustment for potential confounders. The exposures may, per se, be risk factors for sick leave without relation to pregnancy. Yet, it is still possible that pregnancy further increases the risk of sick leave by the exposures.

In relation to HR for sick leave, we investigated the potential impact of pregnancy week period for each exposure; this knowledge is of importance in terms of preventing sick leave at potentially high risk pregnancy week periods. We did find time-dependency for some of the exposures; however, modifications of exposure levels over time during pregnancy may play a role in this time-dependency, and the time-dependent effects we found were small.

The strengths of our study include the large study size and the wide range of prospectively collected possible confounders, for which we adjusted. The overall participation rate in the DNBC was around $31 \%$ and varied according to education, occupation, income, and civil 
Table 2. Characteristics of pregnancies with and without first episode of sick leave from first pregnancy interview until 29 completed pregnancy weeks according to descriptors ( $\mathrm{N}=51 \mathrm{874})$ [SD=standard deviation; $\mathrm{ART}=$ =assisted reproductive therapy; BMl=body mass index.]

\begin{tabular}{|c|c|c|c|c|c|c|c|c|}
\hline \multirow[t]{2}{*}{ Parameter } & \multicolumn{4}{|c|}{$\begin{array}{c}\text { Sick leave a } \\
\mathrm{N}=10667(20.6 \%)\end{array}$} & \multicolumn{4}{|c|}{$\begin{array}{c}\text { No sick leave a } \\
\mathrm{N}=41207(79.4 \%)\end{array}$} \\
\hline & $\mathrm{N}$ & $\%$ & Mean & SD & $\mathrm{N}$ & $\%$ & Mean & SD \\
\hline Pregnancy week at time of first interview & & & 16.4 & 3.8 & & & 17.6 & 4.2 \\
\hline Age (years) & & & 30.1 & 4.2 & & & 30.7 & 4.0 \\
\hline \multicolumn{9}{|l|}{ Age group (years) } \\
\hline$<20$ & 21 & 0.2 & & & 85 & 0.2 & & \\
\hline $20-<30$ & 4967 & 46.6 & & & 16473 & 40.0 & & \\
\hline $30-<40$ & 5488 & 51.4 & & & 23891 & 58.0 & & \\
\hline$\geq 40$ & 191 & 1.8 & & & 758 & 1.8 & & \\
\hline \multicolumn{9}{|l|}{ Lifestyle smoking } \\
\hline Smoking & 1904 & 17.9 & & & 4722 & 11.5 & & \\
\hline \multicolumn{9}{|l|}{ Lifestyle alcohol, weekly intake (drinks ${ }^{b}$ ) } \\
\hline 0 & 6213 & 58.3 & & & 20555 & 49.9 & & \\
\hline$\leq 2$ & 3910 & 36.7 & & & 17938 & 43.5 & & \\
\hline $2-7$ & 514 & 4.8 & & & 2606 & 6.3 & & \\
\hline$>7$ & 18 & 0.2 & & & 61 & 0.2 & & \\
\hline \multicolumn{9}{|l|}{ Occupational class } \\
\hline Higher grade professionals & 1279 & 12.0 & & & 10176 & 24.7 & & \\
\hline Lower grade professionals & 3619 & 33.9 & & & 13755 & 33.4 & & \\
\hline Skilled workers & 4844 & 45.4 & & & 15501 & 37.6 & & \\
\hline Unskilled workers & 889 & 8.3 & & & 1651 & 4.0 & & \\
\hline \multicolumn{9}{|c|}{ Sickness absence two years before study entry (weeks) } \\
\hline 0 & 6836 & 64.1 & & & 32389 & 78.6 & & \\
\hline $1-4$ & 2146 & 20.1 & & & 4501 & 10.9 & & \\
\hline $5-8$ & 528 & 5.0 & & & 895 & 2.2 & & \\
\hline $9-26$ & 599 & 5.6 & & & 1492 & 3.6 & & \\
\hline$>26$ & 558 & 5.2 & & & 1930 & 4.7 & & \\
\hline \multicolumn{9}{|l|}{ Chronic diseases ${ }^{c}$} \\
\hline Yes & 1263 & 11.8 & & & 3463 & 8.4 & & \\
\hline \multicolumn{9}{|l|}{ Parity } \\
\hline Multiparous & 6314 & 59.2 & & & 21140 & 51.3 & & \\
\hline \multicolumn{9}{|l|}{ Pre-pregnancy body mass index $\left(\mathrm{kg} / \mathrm{m}^{2}\right)$} \\
\hline$\leq 18.5$ & 423 & 4.0 & & & 1659 & 4.0 & & \\
\hline $18.5-<25$ & 6802 & 63.8 & & & 28953 & 70.3 & & \\
\hline $25-<30$ & 2272 & 21.3 & & & 7371 & 17.9 & & \\
\hline$\geq 30$ & 997 & 9.4 & & & 2593 & 6.3 & & \\
\hline \multicolumn{9}{|l|}{ Assisted reproductive therapy (ART) } \\
\hline Yes & 583 & 5.5 & & & 2276 & 5.5 & & \\
\hline \multicolumn{9}{|l|}{ Support from colleagues at work } \\
\hline Often & 7718 & 72.4 & & & 30341 & 73.6 & & \\
\hline Sometimes & 1967 & 18.4 & & & 7707 & 18.7 & & \\
\hline Seldom & 763 & 7.2 & & & 2406 & 5.8 & & \\
\hline
\end{tabular}

a Percentages do not add up to 100 due to missing values: smoking $(\mathrm{N}=16)$, alcohol intake ( $\mathrm{N}=59$ ), physical demanding work ( $\mathrm{N}=741)$, psychological demanding work $(N=740)$, occupational class $(N=160)$, chronic diseases $(N=86)$, parity $(N=2)$, BMI $(N=804), A R T(N=24)$, support from colleagues ( $N=972)$.

${ }^{b}$ One drink 12 grams of alcohol corresponds to either one beer $(33 \mathrm{cl})$, one glass of wine $(12.5 \mathrm{cl})$ or one glass of spirits $(4 \mathrm{cl})$.

c Self-reported in early pregnancy interview. Combined into a measure of diseases that have been present and caused symptoms during pregnancy; the variable included (metabolic diseases, hypertension, urinary tract diseases (not cystitis), musculoskeletal diseases, psychiatric disorders and other severe somatic diseases).

status (25). Non-participation in the DNBC was caused by either the general practitioners (approximately $50 \%$ participated) or the women themselves (approximately $60 \%$ participated). This selection, which was partially associated with socioeconomic factors and occupational class, could lead to collider stratification bias. However, we believe that the adjustment for occupational class in the statistical analyses minimizes important bias due to this selection. Even so, selection into the DNBC can affect the external validity of our study, and our results may not apply to other populations of pregnant women.

Information on exposures and covariates was based on self-reports and could be subject to misclassifica- tion. Occupational exposure information was collected around pregnancy week 17 , and exposures relevant at this time point may not be valid throughout the pregnancy period. Adjustments in the work environment during pregnancy among highly exposed women may underestimate true associations.

Outcome data were register-based. Owing to variations in sick leave registration in DREAM, sick leave prevalence is most likely underestimated, since nonpregnancy-related short-term sick leave is not registered. Underestimation of the outcome is, however, not believed to be associated with the exposures and would therefore most likely not bias the HR. DREAM was 
Table 3. Crude and adjusted hazard ratios (HR) of first episode of sick leave during 10-29 completed pregnancy weeks according to occupational exposures. The Danish National Birth Cohort (DNBC) 1996-2002 ( $\mathrm{N}=49$ 195). a [95\% Cl=95\% confidence interval.]

\begin{tabular}{|c|c|c|c|c|c|c|c|c|}
\hline & Events (N) & Subjects $(\mathrm{N})^{\mathrm{a}}$ & $\mathrm{HR}_{\text {crude }}$ & $95 \% \mathrm{Cl}$ & $\mathrm{HR}_{\mathrm{adj}} \mathrm{b}^{\mathrm{s}}$ & $95 \% \mathrm{Cl}$ & $\mathrm{HR}_{\mathrm{adj}} \mathrm{c}^{\mathrm{c}}$ & $95 \% \mathrm{Cl}$ \\
\hline \multicolumn{9}{|l|}{ Work posture } \\
\hline Primarily standing & 678 & 2037 & 3.22 & $2.94-3.52$ & 2.75 & $2.51-3.02$ & 2.57 & $2.34-2.82$ \\
\hline Primarily walking & 1135 & 3274 & 3.37 & $3.12-3.64$ & 2.96 & $2.74-3.20$ & 2.74 & $2.54-2.96$ \\
\hline Primarily standing and walking & 2163 & 6170 & 3.42 & $3.20-3.65$ & 2.98 & $2.79-3.18$ & 2.80 & $2.62-2.99$ \\
\hline Primarily sitting & 1565 & 13711 & 1.0 &.. & 1.0 &.. & 1.0 & .. \\
\hline Changeable & 4401 & 23735 & 1.67 & $1.57-1.77$ & 1.56 & $1.47-1.65$ & 1.54 & $1.46-1.64$ \\
\hline Other d & 74 & 263 & 2.54 & $2.01-3.21$ & 2.36 & $1.87-2.98$ & 2.23 & $1.77-2.82$ \\
\hline \multicolumn{9}{|l|}{ Daily lifts $11-20 \mathrm{~kg}$} \\
\hline Yes & 3987 & 12030 & 2.19 & $2.11-2.28$ & 1.92 & $1.84-2.00$ & 1.77 & $1.70-1.84$ \\
\hline No & 6029 & 37165 & 1.0 &.. & 1.0 &.. & 1.0 & .. \\
\hline \multicolumn{9}{|l|}{ Daily lifts $>20 \mathrm{~kg}$} \\
\hline Yes & 2140 & 5622 & 2.29 & $2.18-2.40$ & 1.96 & $1.87-2.06$ & 1.83 & $1.74-1.92$ \\
\hline No & 7876 & 43573 & 1.0 &.. & 1.0 &.. & 1.0 & .. \\
\hline \multicolumn{9}{|l|}{ Cumulative daily lifting kg } \\
\hline $0-14$ & 6201 & 38067 & 1.0. & .. & 1.0 &.. & 1.0 & .. \\
\hline $15-100$ & 1818 & 6264 & 1.87 & $1.78-1.97$ & 1.70 & $1.61-1.79$ & 1.58 & $1.49-1.67$ \\
\hline $101-200$ & 831 & 2196 & 2.53 & $2.36-2.73$ & 2.19 & $2.03-2.36$ & 2.01 & $1.87-2.17$ \\
\hline $201-500$ & 768 & 1853 & 2.88 & $2.67-3.11$ & 2.39 & $2.21-2.58$ & 2.18 & $2.02-2.35$ \\
\hline $501-1000$ & 260 & 574 & 3.23 & $2.85-3.66$ & 2.51 & $2.21-2.84$ & 2.26 & $1.99-2.56$ \\
\hline$>1000$ & 138 & 241 & 4.59 & $3.87-5.43$ & 3.55 & $3.00-4.21$ & 3.02 & $2.54-3.58$ \\
\hline $\begin{array}{l}\text { Trend cumulative lifting e } \\
\text { Work shift }{ }^{f}\end{array}$ & . & . & 1.42 & $1.39-1.44$ & 1.33 & $1.31-1.35$ & 1.29 & $1.27-1.31$ \\
\hline Fixed day & 7351 & 40466 & 1.0 & .. & 1.0 & .. & 1.0 & .. \\
\hline Fixed evening & 437 & 1034 & 2.45 & $2.23-2.70$ & 2.08 & $1.89-2.29$ & 1.89 & $1.72-2.09$ \\
\hline Fixed night & 158 & 364 & 2.76 & $2.35-3.22$ & 1.54 & $1.16-2.03$ & 1.48 & $1.12-1.96$ \\
\hline Shifting, without night shifts & 969 & 3673 & 1.46 & $1.36-1.56$ & 1.44 & $1.35-1.54$ & 1.46 & $1.37-1.57$ \\
\hline Shifting, with night shifts & 1101 & 3658 & 1.67 & $1.56-1.78$ & 1.58 & $1.39-1.80$ & 1.61 & $1.42-1.83$ \\
\hline \multicolumn{9}{|l|}{ Average monthly night shifts } \\
\hline 0 & 8757 & 45173 & 1.0 & .. & 1.0 &.. & 1.0 & .. \\
\hline$<1$ & 84 & 250 & 1.75 & $1.41-2.17$ & 1.74 & $1.40-2.15$ & 1.71 & $1.38-2.12$ \\
\hline $1-2$ & 248 & 861 & 1.49 & $1.31-1.69$ & 1.48 & $1.31-1.68$ & 1.51 & $1.33-1.71$ \\
\hline $3-4$ & 390 & 1322 & 1.52 & $1.37-1.68$ & 1.57 & $1.42-1.74$ & 1.67 & $1.51-1.85$ \\
\hline $5-6$ & 194 & 639 & 1.57 & $1.37-1.82$ & 1.61 & $1.40-1.86$ & 1.72 & $1.49-1.99$ \\
\hline $7-8$ & 101 & 399 & 1.27 & $1.04-1.55$ & 1.29 & $1.06-1.57$ & 1.31 & $1.08-1.60$ \\
\hline$>8$ & 242 & 551 & 2.58 & $2.27-2.93$ & 2.08 & $1.83-2.36$ & 1.89 & $1.67-2.15$ \\
\hline Trend weekly night shifts e & . & . & 1.06 & $1.05-1.07$ & 1.05 & $1.04-1.06$ & 1.04 & $1.04-1.05$ \\
\hline \multicolumn{9}{|l|}{ Weekly work hours } \\
\hline$<30$ hours & 1877 & 7695 & 1.27 & $1.20-1.34$ & 1.12 & $1.07-1.19$ & 1.08 & $1.03-1.14$ \\
\hline $30-<37$ hours & 1633 & 6254 & 1.39 & $1.31-1.47$ & 1.26 & $1.19-1.34$ & 1.21 & $1.15-1.28$ \\
\hline 37 hours & 5534 & 28510 & 1.0 &.. & 1.0 &.. & 1.0 & .. \\
\hline$>37$ hours & 972 & 6736 & 0.74 & $0.69-0.79$ & 0.81 & $0.76-0.87$ & 0.88 & $0.82-0.95$ \\
\hline $\begin{array}{l}\text { Trend weekly work hourse } \\
\text { Job strain }\end{array}$ & . & . & 0.84 & $0.83-0.86$ & 0.90 & $0.88-0.92$ & 0.93 & $0.91-0.95$ \\
\hline High strain & 1201 & 3292 & 1.76 & $1.64-1.88$ & 1.60 & $1.49-1.71$ & 1.51 & $1.41-1.62$ \\
\hline Passive & 1025 & 4028 & 1.10 & $1.02-1.18$ & 1.02 & $0.95-1.10$ & 0.94 & $0.87-1.01$ \\
\hline Active & 2604 & 11345 & 1.0 &.. & 1.0 &.. & 1.0 & .. \\
\hline Low strain & 5186 & 30580 & 0.70 & $0.67-0.74$ & 0.70 & $0.67-0.74$ & 0.70 & $0.67-0.73$ \\
\hline
\end{tabular}

${ }^{a}$ Complete case analyses only, 2679 observations dropped due to missing values on covariates or exposures.

${ }^{\mathrm{b}}$ Adjusted for age, smoking, alcohol intake, level of sickness absence two years prior to the DNBC pregnancy, chronic diseases, parity, body mass index (BMI), assisted reproductive therapy (ART), and support from colleagues.

${ }^{c}$ Adjusted as in $b$ and additionally for occupational class.

${ }^{\mathrm{d}}$ Cycling, kneeling, standing combined with sitting.

${ }^{e}$ Variables entered as continuous categorical (cumulative daily lifting, weekly work hours) and continuous (average monthly night shifts).

${ }^{\dagger}$ Additionally adjusted for number of night shifts per month.

recently validated in a study comparing employer registration of sickness absence with DREAM registration (26). The sensitivity and the specificity were very high for ordinary sick leave, but very low for pregnancyrelated sick leave (26). We believe that this could be due to the exclusion of pregnancy-related sick leave or maternity leave (DREAM code 881) from the analyses. Based on our data, code 881 accounted for $97 \%$ of all sick leaves at the time of 29 completed pregnancy weeks. A validation of DREAM data in relation to sick leave during pregnancy is thus still required.

We adjusted for a number of possible confounders, yet we cannot rule out residual confounding and confounding by variables not included in the models. Adjustment for pregnancy-related disorders diagnosed by the women's general practitioner or obstetrician would have been 
Table 4. Adjusted hazard ratios $\left(\mathrm{HR}_{\mathrm{adj}}\right)$ of first episode of sick leave in four pregnancy week intervals according to work related exposures. The Danish National Birth Cohort (DNBC) 1996-2002 ( $\mathrm{N}=51$ 874). [TVC=time varying coefficient; $95 \% \mathrm{Cl}=95 \%$ confidence interval.]

\begin{tabular}{|c|c|c|c|c|c|c|c|c|c|c|}
\hline & \multicolumn{8}{|c|}{ Completed pregnancy week period } & \multirow[t]{3}{*}{ TVC a } & \multirow[t]{3}{*}{$95 \% \mathrm{Cl}$} \\
\hline & \multicolumn{2}{|c|}{$10-14(\mathrm{~N}=13969)$} & \multicolumn{2}{|c|}{$15-19(\mathrm{~N}=36638)$} & \multicolumn{2}{|c|}{$20-24(\mathrm{~N}=46$ 129) } & \multicolumn{2}{|c|}{$25-29(\mathrm{~N}=45573)$} & & \\
\hline & $\mathrm{HR}_{\mathrm{adj}} \mathrm{b}$ & $95 \% \mathrm{Cl}$ & $\mathrm{HR}_{\mathrm{adj}} \mathrm{b}$ & $95 \% \mathrm{Cl}$ & $\mathrm{HR}_{\mathrm{adj}} \mathrm{b}^{\mathrm{s}}$ & $95 \% \mathrm{Cl}$ & $\mathrm{HR}_{\mathrm{adj}} \mathrm{b}^{\mathrm{s}}$ & $95 \% \mathrm{Cl}$ & & \\
\hline \multicolumn{11}{|l|}{ Work posture } \\
\hline Primarily standing & 2.22 & $1.42-3.48$ & 2.46 & $1.96-3.08$ & 2.60 & $2.22-3.06$ & 2.68 & $2.34-3.06$ & 0.99 & $0.98-1.02$ \\
\hline Primarily walking & 2.19 & $1.47-3.26$ & 2.96 & $2.45-3.56$ & 2.88 & $2.51-3.29$ & 2.63 & $2.34-2.95$ & 0.99 & $0.97-1.01$ \\
\hline Primarily standing and walking & 2.43 & $1.71-3.43$ & 2.90 & $2.46-3.42$ & 2.92 & $2.60-3.28$ & 2.72 & $2.47-2.99$ & 0.99 & $0.98-1.01$ \\
\hline Primarily sitting & 1.00 & .. & 1.00 & .. & 1.00 & & 1.00 & & & \\
\hline Changeable & 1.60 & $1.17-2.20$ & 1.75 & $1.51-2.03$ & 1.53 & $1.38-1.70$ & 1.49 & $1.38-1.62$ & 0.99 & $0.98-1.00$ \\
\hline Other ${ }^{\mathrm{c}}$ & 3.20 & $1.44-7.09$ & 3.05 & $1.89-4.93$ & 2.24 & $1.48-3.41$ & 1.72 & $1.17-2.55$ & 0.95 & $0.90-0.99$ \\
\hline \multicolumn{11}{|l|}{ Daily lifts $11-20 \mathrm{~kg}$} \\
\hline Yes & 1.49 & $1.22-1.82$ & 1.91 & $1.73-2.10$ & 1.85 & $1.72-1.98$ & 1.71 & $1.61-1.82$ & 0.99 & $0.98-0.99$ \\
\hline No & 1.00 & .. & 1.00 & .. & 1.00 & .. & 1.00 & .. & & \\
\hline \multicolumn{11}{|l|}{ Daily lifts $>20 \mathrm{~kg}$} \\
\hline Yes & 1.78 & $1.44-2.21$ & 1.97 & $1.78-2.20$ & 1.89 & $1.74-2.05$ & 1.76 & $1.63-1.89$ & 0.99 & $0.98-0.99 d$ \\
\hline No & 1.00 & .. & 1.00 & .. & 1.00 & .. & 1.00 & .. & & \\
\hline \multicolumn{11}{|l|}{ Cumulative daily lifting $(\mathrm{kg})$} \\
\hline $0-14$ & 1.00 & .. & 1.00 & .. & 1.00 &. & 1.00 & .. & & \\
\hline $15-100$ & 1.17 & $0.88-1.54$ & 1.66 & $1.47-1.88$ & 1.59 & $1.45-1.74$ & 1.58 & $1.46-1.71$ & 0.99 & $0.99-1.01$ \\
\hline $101-200$ & 2.10 & $1.55-2.85$ & 2.04 & $1.73-2.41$ & 2.06 & $1.82-2.34$ & 1.93 & $1.72-2.16$ & 0.99 & $0.97-1.00$ \\
\hline $201-500$ & 1.83 & $1.30-2.58$ & 2.35 & $1.99-2.77$ & 2.21 & $1.94-2.52$ & 2.08 & $1.84-2.34$ & 0.99 & $0.97-1.00$ \\
\hline $501-1000$ & 1.71 & $0.97-3.00$ & 2.57 & $1.99-3.32$ & 2.07 & $1.66-2.59$ & 2.28 & $1.86-2.78$ & 0.98 & $0.96-1.01$ \\
\hline$>1000$ & 3.53 & $1.99-6.26$ & 2.68 & $1.82-3.95$ & 3.04 & $2.27-4.08$ & 3.06 & $2.32-4.04$ & 0.99 & $0.96-1.03$ \\
\hline Trend cumulative lifting $\mathrm{e}$ & 1.25 & $1.16-1.34$ & 1.30 & $1.25-1.34$ & 1.28 & $1.25-1.32$ & 1.28 & $1.25-1.32$ & & \\
\hline \multicolumn{11}{|l|}{ Work shift ${ }^{\dagger}$} \\
\hline Day & 1.00 & .. & 1.00 & .. & 1.00 & .. & 1.00 & .. & & \\
\hline Evening & 1.32 & $0.87-2.02$ & 1.86 & $1.52-2.27$ & 1.81 & $1.53-2.14$ & 2.09 & $1.80-2.42$ & 1.01 & $0.99-1.03$ \\
\hline Night & 4.52 & $1.12-18.32$ & 0.86 & $0.48-1.55$ & 2.00 & $1.21-3.31$ & 1.47 & $0.95-2.27$ & 0.99 & $0.96-1.02$ \\
\hline Shifting, without night shifts & 1.22 & $0.88-1.69$ & 1.38 & $1.18-1.62$ & 1.40 & $1.24-1.57$ & 1.58 & $1.44-1.75$ & 1.02 & $1.00-1.03^{d}$ \\
\hline Shifting, with night shifts & 1.61 & $0.92-2.83$ & 1.40 & $1.03-1.90$ & 1.45 & $1.15-1.82$ & 1.79 & $1.49-2.14$ & 1.02 & $1.01-1.04^{d}$ \\
\hline \multicolumn{11}{|l|}{ Average monthly night shifts } \\
\hline 0 & 1.00 & .. & 1.00 & .. & 1.00 & .. & 1.00 &.. & & \\
\hline$<1$ & 0.75 & $0.19-3.03$ & 2.18 & $1.42-3.36$ & 1.04 & $0.65-1.66$ & 2.26 & $1.71-3.00$ & 1.04 & -1.09 \\
\hline $1-2$ & 1.54 & $0.88-2.70$ & 1.30 & $0.96-1.76$ & 1.37 & $1.09-1.72$ & 1.66 & $1.38-1.98$ & 1.02 & $0.99-1.05$ \\
\hline $3-4$ & 1.50 & $0.91-2.47$ & 1.66 & $1.30-2.10$ & 1.61 & $1.34-1.93$ & 1.78 & $1.54-2.07$ & 1.02 & $0.99-1.04$ \\
\hline $5-6$ & 1.96 & $1.07-3.61$ & 1.54 & $1.09-2.19$ & 1.64 & $1.28-2.11$ & 1.83 & $1.49-2.26$ & 1.02 & $0.99-1.05$ \\
\hline $7-8$ & 0.75 & $0.24-2.33$ & 1.26 & $0.80-1.99$ & 1.23 & $0.87-1.75$ & 1.44 & $1.09-1.90$ & 1.02 & $0.98-1.07$ \\
\hline$>8$ & 1.30 & $0.71-2.38$ & 2.11 & $1.62-2.73$ & 1.89 & $1.52-2.35$ & 1.78 & $1.44-2.19$ & 0.99 & $0.96-1.02$ \\
\hline Trend cumulative shifts ${ }^{d}$ & 1.02 & $0.99-1.05$ & 1.05 & $1.04-1.06$ & 1.04 & 1.03-1.05 & 1.04 & $1.03-1.06$ & & \\
\hline \multicolumn{11}{|l|}{ Weekly work hours } \\
\hline$<30$ hours & 0.86 & $0.67-1.12$ & 1.15 & $1.02-1.30$ & 1.10 & $1.00-1.20$ & 1.07 & -1.16 & 0.99 & $0.98-1.00$ \\
\hline $30-<37$ hours & 0.97 & $0.74-1.27$ & 1.12 & $0.98-1.28$ & 1.36 & $1.24-1.49$ & 1.16 & $1.07-1.27$ & 1.00 & $0.98-1.01$ \\
\hline 37 hours & 1.00 & .. & 1.00 & .. & 1.00 & & 1.00 & & & \\
\hline$>37$ hours & 0.83 & $0.58-1.18$ & 0.90 & $0.76-1.06$ & 0.84 & $0.74-0.95$ & 0.91 & $0.83-1.01$ & 1.01 & $0.99-1.02$ \\
\hline Trend weekly work hours ${ }^{d}$ & 1.03 & $0.92-1.14$ & 0.92 & $0.88-0.97$ & 0.91 & $0.88-0.95$ & 0.95 & $0.92-0.98$ & & \\
\hline \multicolumn{11}{|l|}{ Job strain } \\
\hline High strain & 1.53 & $1.11-2.11$ & 1.64 & $1.41-1.92$ & 1.50 & $1.34-1.69$ & 1.48 & $1.33-1.65$ & 0.99 & $0.97-1.00$ \\
\hline Passive & 0.91 & $0.65-1.28$ & 1.10 & $0.93-1.29$ & 0.88 & $0.78-1.00$ & 0.94 & $0.84-1.05$ & 0.98 & $0.97-0.99 \mathrm{~d}$ \\
\hline Active & 1.00 & .. & 1.00 & .. & 1.00 & & 1.00 & & & \\
\hline Low strain & 0.70 & $0.55-0.88$ & 0.71 & $0.63-0.79$ & 0.66 & $0.61-0.72$ & 0.73 & $0.68-0.78$ & 1.00 & $0.99-1.02$ \\
\hline \multicolumn{11}{|c|}{$\begin{array}{l}\text { a } H R \text { for each pregnancy week can be calculated by using the formula: HR pregnancy week }(x)=H R_{\text {pregnancyweek }} 10 \times T V C \text { pregnancy week }(x) \text {. If } T V C>1, H R \\
\text { increases with time and if } T V C<1 \text {, HR decreases with time. }\end{array}$} \\
\hline \multirow{2}{*}{\multicolumn{11}{|c|}{$\begin{array}{l}\text { 'Adjusted for age, smoking, alcohol intake, occupational class, sickness absence prior to the DNBC pregnancy, chronic diseases, parity, body mass index } \\
\text { (BMI), assisted reproductive therapy (ART), and support from colleagues. } \\
\text { 'Cycling, kneeling, standing combined with sitting. }\end{array}$}} \\
\hline & & & & & & & & & & \\
\hline 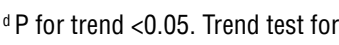 & & & & & & & & & & \\
\hline
\end{tabular}


relevant, but, unfortunately, we did not have these data.

We did, however, make a sub-analysis using information from the second pregnancy interview on a number of pregnancy-related disorders. The sub-analysis did not indicate considerable confounding caused by these pregnancy-related disorders; yet other disorders that were not included in the sub-analysis may potentially confound our findings. Due to correlation between exposures and occupational class, adjustment for occupational class may lead to over-adjustment, as indicated by the results in table 3 .

The risk of adverse birth outcomes such as foetal death, preterm labor and low birth weight have been investigated in a number of studies in relation to physical and psychosocial work exposures, and the results of these studies have been conflicting (27-31). In general, if present, elevated risks for adverse birth outcomes are small, and currently there is no evidence to impose limits of physical exposures such as lifting, walking, or standing or even to discourage the exposures among healthy pregnant women. Though not including high risks for adverse birth outcomes, the exposures investigated in the present study may impose physical discomfort that may result in sick leave. Other factors of importance for taking sick leave such as health beliefs and personality may confound our results if these factors are associated with the exposures. Women in the high-exposures groups may believe that high exposures are harmful to the foetus and thereby be more inclined to take sick leave.

Our study has several implications if our findings reflect causal associations. Workplaces providing either sitting work or, if this is not possible, changeable work postures may lower the risk for sick leave among their employees. Sick leave may also be reduced by exemption from non-daytime work, by reducing single lifts $>11$ $\mathrm{kg}$ and minimizing cumulative daily lifting. Women in strained jobs may reduce their risk for sick leave during pregnancy by obtaining more control in their jobs. Arranging work adjustments during pregnancy may not be straightforward; it requires flexibility, determination, and a good working relationship between employers and all employees. No randomized controlled trials have so far investigated if active reorganization of occupational exposures during pregnancy may reduce the incidence of sick leave among pregnant women.

In summary, in this population-based cohort of employed women, we found that non-sitting work postures, lifting, shift work, and high job strain were associated with increased risk for sick leave from 10-29 completed pregnancy weeks. These findings largely corroborate findings from earlier, smaller studies. If our findings reflect causal relations, changes in the work environment for pregnant women may reduce sick leave. Such changes and their potential effect should be investigated in future studies.

\section{Acknowledgements}

The Danish National Research Foundation has established the Danish Epidemiology Science Centre that initiated and created the Danish National Birth Cohort. The cohort is furthermore a result of a major grant from this Foundation. Additional support for the Danish National Birth Cohort is obtained from the Pharmacy Foundation, the Egmont Foundation, the March of Dimes Birth Defects Foundation, the Augustinus Foundation and the Health Foundation.

The authors thank data manager Jesper Medom Vestergaard, Department of Occupational Medicine, Danish Ramazzini Centre, Aarhus University Hospital for his great help with management of DREAM data. The authors also thank associate professor, statistician, Morten Frydenberg, Section of Biostatistics, Institute of Public Health, Aarhus University for valuable supervision in the statistical analyses.

\section{References}

1. Sydsjo A, Sydsjo G, Alexanderson K. Influence of pregnancyrelated diagnoses on sick-leave data in women aged 16-44. J Womens Health Gend Based Med. 2001;10(7):707-14. http:// dx.doi.org/10.1089/15246090152563597.

2. Sydsjo G, Sydsjo A. Newly delivered women's evaluation of personal health status and attitudes towards sickness absence and social benefits. Acta Obstet Gynecol Scand. 2002;81(2):104-11. http://dx.doi.org/10.1080/j.16000412.2002.810203.x.

3. Kaerlev L, Jacobsen LB, Olsen J, Bonde JP. Long-term sick leave and its risk factors during pregnancy among Danish hospital employees. Scand J Public Health. 2004;32(2):111-7. http://dx.doi.org/10.1080/14034940310017517.

4. Petersen KR, Hording U, Roepstorff C, Kamper-Jorgensen F, Larsen JF. Self-reported pattern of illness and hospitalization during pregnancy. Results from a nation-wide questionnaire study. Ugeskr Laeger. 1989;151(10):621-5.

5. Markussen S, Rogeberg O. Sickness absence associated with major life events - original language Sykefravær rundt større livshendelser. Tidsskr Nor Laegeforen. 2012;132(10):1231-4. http://dx.doi.org/10.4045/tidsskr.11.0252.

6. Alexanderson K, Hensing G, Carstensen J, Bjurulf P. Pregnancy-related sickness absence among employed women in a Swedish county. Scand J Work Environ Health. 1995;21(3):191-8. http://dx.doi.org/10.5271/sjweh.27.

7. Sydsjo A, Sydsjo G, Kjessler B. Sick leave and social benefits during pregnancy--a Swedish-Norwegian comparison. Acta Obstet Gynecol Scand. 1997;76(8):748-54. http://dx.doi. org/10.3109/00016349709024341.

8. Sydsjo G, Sydsjo A, Wijma B. Variations in sickness 
absence and use of social benefits among pregnant women in a Swedish community 1978-1997. Acta Obstet Gynecol Scand. 1999;78(5):383-7. http://dx.doi.org/10.1080/j.16000412.1999.780507.x.

9. Hansen ML, Ane Marie T, Juhl M, Kristensen JK, RamlauHansen $\mathrm{CH}$. Predictors of sickness absence in pregnancy: a Danish cohort study. Scand J Work Environ Health. 2015;41(2):184-93. http://dx.doi.org/10.5271/sjweh.3470.

10. Kristensen P, Nordhagen R, Wergeland E, Bjerkedal T. Job adjustment and absence from work in mid-pregnancy in the Norwegian Mother and Child Cohort Study (MoBa). Occup Environ Med. 2008;65(8):560-6. http://dx.doi.org/10.1136/ oem.2007.035626.

11. Strand K, Wergeland E, Bjerkedal T. Job adjustment as a means to reduce sickness absence during pregnancy. Scand J Work Environ Health. 1997;23(5):378-84. http://dx.doi. org/10.5271/sjweh.235.

12. Strand K, Wergeland E, Bjerkedal T. Work load, job control and risk of leaving work by sickness certification before delivery, Norway 1989. Scand J Soc Med. 1997;25(3):193201. http://dx.doi.org/10.1177/140349489702500308.

13. Olsen J, Melbye M, Olsen SF, Sorensen TI, Aaby P, Andersen AM, et al. The Danish National Birth Cohort--its background, structure and aim. Scand J Public Health. 2001;29(4):300-7. http://dx.doi.org/10.1177/14034948010290040201.

14. Karasek RA. Job Demands, Job Decision Latitude, and Mental Strain: Implications for Job Redesign. Administrative Science Quarterly. 1979;24(2):285-308. http://dx.doi. org/10.2307/2392498.

15. Zhu JL, Hjollund NH, Andersen AM, Olsen J. Shift work, job stress, and late fetal loss: The National Birth Cohort in Denmark. J Occup Environ Med. 2004;46(11):1144-9. http:// dx.doi.org/10.1097/01.jom.0000145168.21614.21.

16. Juhl M, Andersen PK, Olsen J, Andersen AM. Psychosocial and physical work environment, and risk of pelvic pain in pregnancy. A study within the Danish national birth cohort. J Epidemiol Community Health. 2005;59(7):580-5. http:// dx.doi.org/10.1136/jech.2004.029520.

17. Larsen AD, Hannerz H, Juhl M, Obel C, Thulstrup AM, Bonde JP, et al. Psychosocial job strain and risk of adverse birth outcomes: a study within the Danish national birth cohort. Occup Environ Med. 2013;70(12):845-51. http://dx.doi. org/10.1136/oemed-2013-101453.

18. Rasmussen J. Danish Register for Evaluation of Marginalisation (DREAM), Danish Ministry of Employment, Copenhagen, 2012; Available from: http://www.dst.dk/da/TilSalg/ Forskningsservice/Data/Andre_styrelser.aspx. Accessed 01/30, 2014.

19. Alexanderson K, Hensing G, Leijon M, Akerlind I, Rydh H, Carstensen J, et al. Pregnancy related sickness absence in a Swedish county, 1985-87. J Epidemiol Community Health. 1994;48(5):464-70. http://dx.doi.org/10.1136/jech.48.5.464.

20. Dorheim SK, Bjorvatn B, Eberhard-Gran M. Sick leave during pregnancy: a longitudinal study of rates and risk factors in a Norwegian population. BJOG. 2013;120(5):521-30. http:// dx.doi.org/10.1111/1471-0528.12035.
21. Alavinia SM, van den Berg TI, van Duivenbooden C, Elders LA, Burdorf A. Impact of work-related factors, lifestyle, and work ability on sickness absence among Dutch construction workers. Scand J Work Environ Health. 2009;35(5):325-33. http://dx.doi.org/10.5271/sjweh.1340.

22. d'Errico A, Costa G. Socio-demographic and work-related risk factors for medium- and long-term sickness absence among Italian workers. Eur J Public Health. 2012;22(5):683-8. http:// dx.doi.org/10.1093/eurpub/ckr140.

23. Voss M, Floderus B, Diderichsen F. Physical, psychosocial, and organisational factors relative to sickness absence: a study based on Sweden Post. Occup Environ Med. 2001;58(3):17884. http://dx.doi.org/10.1136/oem.58.3.178.

24. Lund T, Labriola M, Christensen KB, Bultmann U, Villadsen E. Physical work environment risk factors for long term sickness absence: prospective findings among a cohort of 5357 employees in Denmark. BMJ. 2006;25;332(7539):449-52.

25. Jacobsen TN, Nohr EA, Frydenberg M. Selection by socioeconomic factors into the Danish National Birth Cohort. Eur J Epidemiol. 2010;25(5):349-55. http://dx.doi. org/10.1007/s10654-010-9448-2.

26. Stapelfeldt CM, Jensen C, Andersen NT, Fleten N, Nielsen CV. Validation of sick leave measures: self-reported sick leave and sickness benefit data from a Danish national register compared to multiple workplace-registered sick leave spells in a Danish municipality. BMC Public Health. 2012;15(12):661.

27. Bonde JP, Jorgensen KT, Bonzini M, Palmer KT. Miscarriage and occupational activity: a systematic review and metaanalysis regarding shift work, working hours, lifting, standing, and physical workload. Scand J Work Environ Health. 2013;39(4):325-34. http://dx.doi.org/10.5271/sjweh.3337.

28. Palmer KT, Bonzini M, Harris EC, Linaker C, Bonde JP. Work activities and risk of prematurity, low birth weight and pre-eclampsia: an updated review with meta-analysis. Occup Environ Med. 2013;70(4):213-22. http://dx.doi.org/10.1136/ oemed-2012-101032.

29. Snijder CA, Brand T, Jaddoe V, Hofman A, Mackenbach JP, Steegers EA, et al. Physically demanding work, fetal growth and the risk of adverse birth outcomes. The Generation $\mathrm{R}$ Study. Occup Environ Med. 2012;69(8):543-50. http://dx.doi. org/10.1136/oemed-2011-100615.

30. Juhl M, Larsen PS, Andersen PK, Svendsen SW, Bonde JP, Nybo Andersen AM, et al. Occupational lifting during pregnancy and child's birth size in a large cohort study. Scand J Work Environ Health. 2014;40(4):411-9. http://dx.doi. org/10.5271/sjweh.3422.

31. Juhl M, Strandberg-Larsen K, Larsen PS, Andersen PK, Svendsen SW, Bonde JP, et al. Occupational lifting during pregnancy and risk of fetal death in a large national cohort study. Scand J Work Environ Health. 2013;39(4):335-42. http://dx.doi.org/10.5271/sjweh.3335.

Received for publication: 7 January 2015 